IZA DP No. 1232

\title{
Ethnic Networks and International Trade
}

Gil S. Epstein

Ira N. Gang

August 2004 


\title{
Ethnic Networks and International Trade
}

\author{
Gil S. Epstein \\ Bar-llan University, CEPR and IZA Bonn \\ Ira N. Gang \\ Rutgers University and IZA Bonn \\ Discussion Paper No. 1232 \\ August 2004
}

\author{
IZA \\ P.O. Box 7240 \\ 53072 Bonn \\ Germany \\ Phone: +49-228-3894-0 \\ Fax: +49-228-3894-180 \\ Email: iza@iza.org
}

Any opinions expressed here are those of the author(s) and not those of the institute. Research disseminated by IZA may include views on policy, but the institute itself takes no institutional policy positions.

The Institute for the Study of Labor (IZA) in Bonn is a local and virtual international research center and a place of communication between science, politics and business. IZA is an independent nonprofit company supported by Deutsche Post World Net. The center is associated with the University of Bonn and offers a stimulating research environment through its research networks, research support, and visitors and doctoral programs. IZA engages in (i) original and internationally competitive research in all fields of labor economics, (ii) development of policy concepts, and (iii) dissemination of research results and concepts to the interested public.

IZA Discussion Papers often represent preliminary work and are circulated to encourage discussion. Citation of such a paper should account for its provisional character. A revised version may be available directly from the author. 
IZA Discussion Paper No. 1232

August 2004

\section{ABSTRACT}

\section{Ethnic Networks and International Trade*}

There is a well-established high quality literature on the role of networks, particularly ethnic networks, in international trade. Ethnic networks are a way of overcoming informal barriers (information costs, risk and uncertainty) to trade by building trust and substituting for the difficulty of enforcing contracts internationally. The networks we are interested in are those that form between migrants and natives in the host country and between migrants and their home country. Ethnic networks exist when assimilation is not complete. We consider the struggle of migrants to assimilate and, at the same time, the struggle of the local population to prevent such assimilation. These activities affect trade possibilities. Moreover, we show that it may well be in the interest of migrants who specialize in trade to, at some point in time, turn from investing in assimilation activities and instead invest in anti-assimilation activities in order to preserve immigrants' preferences for home country goods.

JEL Classification: D74, F23, I20, J61, L14

Keywords: assimilation, discrimination, contracts, ethnicity, international trade, market structure, network, migration, transnational

Corresponding author:

Ira N. Gang

Economics Department NJH

Rutgers University

75 Hamilton St.

New Brunswick NJ 08901-1248

USA

Email: gang@economics.rutgers.edu

\footnotetext{
* We are grateful for the helpful comment made by the participants in the conference, "Labor Mobility and the World Economy," Kiel Institute for World Economics, June 21-22, 2004.
} 


\section{Ethnic Networks and International Trade}

\section{Introduction}

There is a well-established high quality literature on the role of networks, particularly ethnic networks, in international trade. ${ }^{3}$ Ethnic networks are a way of overcoming informal barriers (information costs, risk and uncertainty) to trade by building trust and substituting for the difficulty of enforcing contracts internationally. The networks we are interested in are those that form between migrants and natives in the host country and between migrants and their home country.

Migrant assimilation is a topic of active research. The literature discusses the speed of the assimilation, the factors advancing and obstructing assimilation, attitudes towards indigenous immigrants, and inter-generational issues. To a degree, the question is how long does it take for immigrants and their families to assimilate into the economic and social structure of the host country. The literature examines first generation immigrants and the length of time, and the factors involved, in achieving earnings parity with the native-born. ${ }^{4}$ There is also some evidence on intergenerational aspects of assimilation (Gang and Zimmermann 2002). While the evidence is mixed, the view that ethnic differences melt away does not hold sway. Though there is much individual variation, on average some ethnic groups do well and some do not. And within ethnic groups, some assimilate, some do not, and some maintain the middle ground.

\footnotetext{
${ }^{3}$ The literature is extensive and largely empirical. It is succinctly summarized and synthesized by Rauch (2001), who himself has made many of the seminal contributions. The fundamental insight is the role of ethnic networks in overcoming the inherent contract enforcement difficulties in international transactions. In this it bears striking similarities to the literature on informal credit markets and microfinance institutions. These have been nice reviewed in Morduch (1999).

${ }^{4}$ The classic paper by Chiswick (1978) starts the modern literature on immigrant wage assimilation. The controversies are summarized by Duleep and Regets (2002) who resolve the main issues. This and other strands of the literature are synthesized in Bauer and Zimmermann (1997). Also see the volume edited by Bauer and Zimmermann (2002) for highlights of the literature.
} 
We examine the consequences of the structure of immigrant assimilation on ethnic trading networks and on international trade. Natives and immigrants may battle each other over above the position of the immigrant in the host country economy (see Gradstein and Schiff, 2004). Natives' view of immigrants, and the conflicts they may form the catalyst for, generate policy towards migrants in the host country. Moreover, immigrants, while desiring to assimilate into the host country culture, may at some point decide their native heritage is something to hold onto. These forces will impact international trade.

Ethnic networks are not fixed, and we expect them to change as immigrants assimilate. In the simplest world, if immigrants completely assimilate and very quickly do so, then there will be no ethnic networks and no gains from them for international trade. At the other extreme where immigrant groups live and work in their own ghetto, with little or no contact with natives, the ethnic enclave is really an extension of the home country and it is questionable whether the effects on international trade will be any more than marginally positive. With just a little less isolation we should see trade gains. Over time, and as a result of immigrant desires for assimilation and host country attitudes, the role networks play changes, with consequences for the international economy.

Our paper is unique in that as far as we know it is the first to explicitly model the role immigrant assimilation plays in international trade. We proceed by constructing a model in which there are three groups of actors, the native-born and two groups of migrants, those who are involved in international trade and those who are not. Migrants are assumed to all be from one home country, and the discussion of trade is with respect to the migrants' host and home countries only. ${ }^{5}$ In this simple model, competition from migrants may lower native-born wages so natives undertake costly discrimination actions against the migrants, while migrants generally are

\footnotetext{
${ }^{5}$ One could also think of networks of migrants from different countries but with the 'same' cultural background (for example Asians, Africans, Arabs, etc.) or a common language. The assumption that all are from the same host country is to simplify our discussion.
} 
assimilating into the host country culture. ${ }^{6} \quad$ We examine the consequences for assimilation and discrimination of increased migration, time, and traders' rents. We also analyze how increased migration, and traders' rents affect trade possibilities. Over time, migrant traders and employees exhibit different interests in assimilation and in maintaining their cultural identity, and we discuss how this affects trade possibilities over time.

\section{The Model}

Consider a host country that has two types of employed workers: Local workers and migrants. Denote the number of local workers by $L_{\mathrm{N}}$ (natives) and migrants (foreigners) by $L_{F}$. Moreover, we consider the case where we have one group of migrants who are employees, and a second group of migrants who are self-employed and engaged in international trade between the host country and the home country.

\subsection{Local population's utility}

Let us consider the utility of the representative local worker. This individual consumes at level $C$ and has positive utility from consumption. Consumption, $C$, is a function of wages of the local worker and as the level of wages is higher, consumption increases. Wages are set equal to the value of marginal product. We normalize the efficiency level of local workers to unity; migrants' efficiency level will be less than unity. The values of the efficiency level of the migrants will be a function of the discrimination activities of the local population and the assimilation activities of the migrants. The efficiency level of the migrants is a function of two elements:

(1) The effort invested by the local population in order to prevent migrants from assimilating into the population: not cooperating with them, anti-assimilation activities, discrimination, and so on (hereafter "discrimination"). Such activities

\footnotetext{
${ }^{6}$ In other words, we are assuming migrants are substitutes for natives in the work force. This is a simplification, as the degree of substitutability and complementarity between natives and migrants depends on the package of productive characteristics each possesses (Gang and Rivera-Batiz, 1994).
} 
decrease the productivity levels of the migrants and thus their efficiency level. ${ }^{7}$ Denote by $d$ the amount of discrimination (or discrimination activities) against migrants.

(2) The effort invested by migrants to assimilate. These activities affect the migrants' efficiency level positively. The more the migrants assimilate, their productivity level increases, as it increases cooperation between the local population and the migrants. Denote assimilation activity by $a .^{8}$

The local individual also has other benefits from the migrants not assimilating into the host country. In general, let us assume that the local worker receives a rent of $n_{N}$ if the migrants are not at all assimilated. This rent is a function of the size of the labor market of local workers, $L_{N}$, and the number of migrants employed by the local population, $L_{F}: n_{N}\left(L_{N}, L_{F}\right)$ such that

$$
\frac{\partial n_{N}\left(L_{N}, L_{F}\right)}{\partial L_{N}}>0 \text { and } \frac{\partial n_{N}\left(L_{N}, L_{F}\right)}{\partial L_{F}}<0 .
$$

As the local population increases (decreasing the relative size of the migrants), rent increases, while as the number of migrants increase (also equaling an increase in the relative number of migrants as we are talking about the partial derivative), the rent of the local population decreases.

We assume that the proportion of migrants who assimilate will be given by the Tullock (1980) function where assimilation and discrimination activities have the following effect: $\frac{a}{a+d}{ }^{9}$. Thus assimilation is relative to the amount of discrimination. For example, if both groups invest one unit in their respective activities, then 50 percent of the immigrants will assimilate. The proportion is also 50 percent if each invests 50 units. There is no cooperation between the groups and therefore the equilibrium level of investment in assimilation and discrimination

\footnotetext{
${ }^{7}$ This is similar to insider-outsider theory by Lindbeck and Snower, 1998.

${ }^{8}$ Assimilation is not always beneficial for migrants (Epstein, 2003). For now, we ignore such possibilities; we will return to discuss them latter in this paper.

${ }^{9}$ See also Lockard and Tullock (2001).
} 
activities will not be at the minimum level. Here, the proportion of migrants who do not assimilate equals $1-\frac{a}{a+d}=\frac{d}{a+d}$.

The utility of a representative local worker is given by :

$$
u_{N}(.)=\frac{d}{d+a} n_{N}\left(L_{N}, L_{F}\right)-d
$$

where $d$ is the level of discrimination. We assume natives face costs in discriminating against migrants and thus it appears negatively in their utility function. As we are considering a representative local worker, it is clear that we may well have a problem of free riding as it is optimal for all local workers together to discriminate against the migrants, however, each worker by himself will not have a reason to discriminate. We assume here that we have solved the free riding problem. An alternative way of looking at this is to think of a case where a union represents the local workers and the union organizes discrimination against migrants. The union, a type of club, overcomes the free rider problem. Of course, one could think of native utility as increasing in the discrimination level, as the native may have a positive utility just from discrimination. This may be the case for some natives; however, overall we assume that it costs natives to participate in discrimination activities. These activities take time and effort and thus decrease the utility of the native. Moreover, note that the effect discrimination activities have on the local worker's utility is also a function of economic conditions in the host country and could well be a function of the wages of the local population. In order to focus our discussion we disregard these effects.

The native's objective is to maximize his utility by determining his optimal discrimination level. The first order condition determining optimal discrimination against migrants in the host country is given by $\frac{\partial u_{N}(.)}{\partial d}=0$. We therefore obtain that the first order conditions can be written in the following way:

$$
\frac{\partial u_{N}(.)}{\partial d}=\frac{a}{(d+a)^{2}} n_{N}\left(L_{N}, L_{F}\right)-1=0
$$


The first order condition therefore satisfies,

$$
\frac{a}{(d+a)^{2}}=\frac{1}{n_{N}\left(L_{N}, L_{F}\right)} \text {. }
$$

In order for the discrimination level determined in (3) to maximize native's utility, the second order condition must hold. The second order condition for maximization is given by $\frac{\partial^{2} u_{N}(.)}{\partial d^{2}}<0$. The second order condition can be calculated and shown to be equal to:

$$
\frac{\partial^{2} u_{N}(.)}{\partial d^{2}}=-2 \frac{a}{(d+a)^{3}} n_{N}\left(L_{N}, L_{F}\right)<0 .
$$

Given the first and second order conditions we can conclude the following:

\section{Lemma 1}

An increase in the natives' rent, either from an increase in the size of the local population or a decrease in the size of the migrant population, will, for a given level of assimilation activities, increase discrimination activities. 


\subsection{The migrant's utility}

We assume that a migrant can either be employed as described above or can be selfemployed (see Lofstrom, 2002, and Le, 1999) trading with his home country. Migrants who have entered the host country may well maintain strong connections with their home country. This gives them an advantage in trading with their home country and in selling their products, which they import, to the residents of the host country. Moreover, the migrants may also sell products of the host country to their home country. To focus our discussion let us think of the migrants as importing products from their home country to their host country.

A different way of looking at this is that many migrants want to continue consuming products that they are used to. The agents who import the products are naturally those who have connections in their home country, and these agents are migrants themselves. Networks to, and in, the home country help self-employed migrants import products and decrease their costs of importing. However, the migrants also need networks in the host country to further decrease the cost of importing (the same would apply in the case of exporting products from the host country to the home country). As the number of migrants who assimilate into the host country increases, the migrants' network externalities increase, enabling them to increase their profits and increase the quantity of imported products, thus increasing the utility of the international importer (exporter) migrant. We therefore have two types of networks that help the migrant increase his rent in importing (exporting) from (to) his home country to (from) the host country: (1) Local networks in the host country - this is measured by the level of migrant assimilation into the host country; and (2) The network in the home country where the migrant still has ties. These ties enable the migrant to trade easier with the different groups in his home country.

As described above, the international trader migrant will benefit from the assimilation of his fellow migrants into the local population. A different way of looking at this is that as the level of assimilation increases, the migrants' wages increase and the consumption of products from their home country increases. ${ }^{10}$

\footnotetext{
${ }^{10}$ What we are modeling here "differential" imports, that is, an import structure that is different from what it would be without the migrants. When we discuss imports increasing or decreasing, we are referring to imports from the home country only.
} 
Under this scenario both employed migrants and self-employed international trade migrants want to increase their level of assimilation. As described above, it is clear that the employed migrant's wage and utility will increase from assimilation; the rent obtained by the international trader migrant will also increase from assimilation. We could think of the total level of assimilation activities, $a$, as the sum of both activities: the assimilation activities of the employed and the traders' assimilation activities. This, however, opens the problem of free riding by both groups. In order to focus our discussion we assume that only one group engages in assimilation activities. For now, we assume that only self-employed international trade migrants invest in the assimilation process. One could think of both parties investing in this process, we simplify matters in order to reduce the problem to a one variable problem. One way of thinking about this is that if the stock of migrants - the employed and the selfemployed - is assumed to be constant, these two levels of investment are proportional to the size of each group. Therefore, we only need to look at one of them. Later in the paper we will relax this assumption.

The utility of the self-employed international trader migrant (IT) at time $t$ is given by,

$$
u(.)_{I T}=R\left(\frac{a}{d+a} n_{I T}\left(L_{F}\right)\right)-a
$$

$R($.$) is the rent associated with trade with the home country. The trader's rent is$ assumed to be a positive function of the number of migrants or their level of assimilation into the host country. This level of assimilation is represented by the term $\frac{a}{d+a} n_{F}\left(L_{F}\right)$. It is assumed that as the level of assimilation increases, $\frac{a}{d+a} n_{I T}\left(L_{F}\right)$ increases, that is, the rent also increases. These migrants participate in assimilation activities and thus have a cost of $a$ for each $a$ units of effort for the purpose of assimilation. To simplify, we assume that the rent from trade equals

Later, we will make clear that as assimilation proceeds, migrants consumption pattern converges to that of natives. 
$R\left(\frac{a}{d+a} n_{I T}\left(L_{F}\right)\right)=r \frac{a}{d+a} n_{I T}\left(L_{F}\right)$. Therefore, the utility of the self-employed international trader migrant becomes

$$
u(.)_{I T}=r \frac{a}{d+a} n_{I T}\left(L_{F}\right)-a .
$$

The first order condition for maximization of the migrant's utility is given by $\frac{\partial u(.)_{I T}}{\partial a}=0$, namely,

$$
\frac{\partial u(.)_{I T}}{\partial a}=\frac{d}{(d+a)^{2}} n_{I T}\left(L_{F}\right) r-1=0 .
$$

The first order condition is satisfied if

$$
\frac{d}{(a+d)^{2}}=\frac{1}{n_{I T}\left(L_{F}\right) r} \text {. }
$$

In order to insure that the solution is the level that maximizes the migrant's utility it must hold that $\frac{\partial^{2} u(.)_{I T}}{\partial a^{2}}<0$. Given the function $\frac{a}{d+a}$ and the assumptions regarding the production function it is clear that the second order conditions hold true:

$$
\frac{\partial^{2} u(.)_{I T}}{\partial a^{2}}=-2 \frac{d}{(d+a)^{3}} n_{I T}\left(L_{F}\right) r<0
$$


From (9) and (10) we can conclude that,

\section{Lemma 2}

Given the level of discrimination, increasing the number of migrants, $L_{F}$, or the trade possibilities, $r$, will increase the level of assimilation activities.

The reason for these results is that increasing these different variables increases the benefits the trader can obtain and thus increases their returns to investing in assimilation. With time, the migrants naturally integrate into the local population, as increasing assimilation activities further enhances integration.

\subsection{Equilibrium}

Natives invest in discrimination activities and migrants invest in assimilation activities ( $a$ and $d$ are positive). We focus on the unique interior Nash equilibria.

Let us calculate the equilibrium discrimination and assimilation activity levels. For this we must simultaneously solve equations (3) and (8), presented below as (3') and $\left(8^{\prime}\right)$ :

$$
\frac{\partial u_{N}(.)}{\partial d}=\frac{d}{(d+a)^{2}} n_{N}\left(L_{N}, L_{F}\right)-1=0,
$$

and,

$$
\frac{\partial u(.)_{I T}}{\partial a}=\frac{d}{(d+a)^{2}} n_{I T}\left(L_{F}\right) r-1=0 .
$$

Solving (3') and ( $\left.8^{\prime}\right)$ we obtain that the equilibrium assimilation level of activities and the equilibrium level of discrimination activities equals: 


$$
a^{*}=\frac{\left(r n_{I T}\left(L_{F}\right)\right)^{2} n_{N}\left(L_{N}, L_{F}\right)}{\left(r n_{I T}\left(L_{F}\right)+n_{N}\left(L_{N}, L_{F}\right)\right)^{2}}
$$

and,

$$
d^{*}=\frac{\left(n_{N}\left(L_{N}, L_{F}\right)\right)^{2} r n_{I T}\left(L_{F}\right)}{\left(r n_{I T}\left(L_{F}\right)+n_{N}\left(L_{N} L_{F}\right)\right)^{2}} \text {. }
$$

It is clear from the above that:

\section{Lemma 3}

Increasing the rents of each group will increase their investment levels. That is, increasing the rent of the local population, given a constant level of the rent for the international trader, will increase discrimination activities. Increasing the rent of the international trader, given a certain level of the rent for the local population, will increase the assimilation activities.

As a change in each of the parameters affects both levels in equilibrium, what effect changes in them will have on equilibrium discrimination and assimilation activities is not straightforward. We now wish to consider the effects changes in the size of the local population have on equilibrium levels of discrimination and assimilation activities.

Note that increasing the size of the local population means increasing the local population's rent. From (9) and (10) we obtain:

$$
\frac{\partial a^{*}}{\partial L_{N}}=\frac{r^{2} n_{I T}^{2}\left(r n_{I T}-n_{N}\right) \frac{\partial n_{N}}{\partial L_{N}}}{\left(r n_{I T}\left(L_{F}\right)+n_{N}\left(L_{N} L_{F}\right)\right)^{3}}
$$


and

$$
\frac{\partial d^{*}}{\partial L_{N}}=\frac{2 r^{2} n_{I T}^{2} n_{N} \frac{\partial n_{N}}{\partial L_{N}}}{\left(r n_{I T}\left(L_{F}\right)+n_{N}\left(L_{N} L_{F}\right)\right)^{3}} .
$$

\section{Proposition 1}

As the size of the local population increases, or as the local population's rent increases, discrimination activities will increase. However, assimilation activities will increase (decrease) if and only if the rent the migrant population can obtain from assimilation activities is greater (smaller) than the local population's rent, $r n_{I T}>n_{N}\left(r n_{I T}<n_{N}\right)$.

This proposition states that local population growth or, equivalently, an increase in the local population's rent, will increase the discrimination activities that the local population undertakes. At the same time, local population growth or an increase in the local population's rent may decrease immigrants' assimilation activities if the rent migrants' gain from assimilation activities is smaller than the benefit the local population can obtain. In other words, strengthening the local population may cause the migrants to decrease their assimilation activities.

This proposition is especially useful for comparing different sized countries. Larger countries, ceteris paribus, will discriminate more against migrants than small countries. Moreover, under certain conditions, in larger countries migrants will assimilate less, maintaining their ethnic enclaves.

Now let is consider the effect an increase in the migrant population has on both types of activities. From (9) and (10 we obtain:

$$
\frac{\partial a^{*}}{\partial L_{F}}=\frac{r^{2} n_{I T}\left(2 n_{N}^{2} \frac{\partial n_{I T}}{\partial L_{F}}+\left(r n_{I T}-n_{N}\right) n_{I T} \frac{\partial n_{N}}{\partial L_{F}}\right)}{\left(r n_{I T}\left(L_{F}\right)+n_{N}\left(L_{N} L_{F}\right)\right)^{3}}
$$


and

$$
\frac{\partial d^{*}}{\partial L_{F}}=\frac{r n_{N}\left(n_{N} \frac{\partial n_{I T}}{\partial L_{F}}\left(n_{N}-r n_{I T}\right)+2 r n_{I T}^{2} \frac{\partial n_{N}}{\partial L_{F}}\right)}{\left(r n_{I T}\left(L_{F}\right)+n_{N}\left(L_{N} L_{F}\right)\right)^{3}} .
$$

Note that increasing the migrant population size increases the rent associated with assimilation activities, $\frac{\partial n_{I T}}{\partial L_{F}}>0$, while increasing the size of the migrant population decreases the rent associated with the discrimination activities, $\frac{\partial n_{N}}{\partial L_{F}}<0$.

\section{Proposition 2}

a. Increasing the size of the migrant population will increase assimilation activities and decrease discrimination activities if and only if the rent the migrant population can obtain from assimilation activities is greater than that of the rent of the local population from discrimination activities $r n_{I T}>n_{N}\left(r n_{I T}<n_{N}\right)$.

b. If the size of the local population increases, it is not clear whether discrimination and assimilation activities will increase or decrease. This will depend on the relative and absolute size of the rents associated with the assimilation and discrimination activities.

By Proposition 2(b), the outcome depends on the asymmetry of the contestants in turning effort into performance and on the value of their benefit from assimilation and discrimination activities.

Now let us consider how a change in the rent, $r$, associated with the trade possibilities affects discrimination and assimilation activities. From (9) and (10) we obtain:

$$
\frac{\partial a^{*}}{\partial r}=\frac{2 r n_{I T}^{2} n_{N}^{2}}{\left(r n_{I T}\left(L_{F}\right)+n_{N}\left(L_{N} L_{F}\right)\right)^{3}}
$$


and

$$
\frac{\partial d^{*}}{\partial r}=\frac{n_{I T} n_{N}^{2}\left(n_{N}-r n_{I T}\right)}{\left(r n_{I T}\left(L_{F}\right)+n_{N}\left(L_{N} L_{F}\right)\right)^{3}} .
$$

We thus obtain that,

\section{Proposition 3}

a. Assimilation activities will increase from increasing the rent associated with international trade, while discrimination (anti-assimilation) activities may increase or decrease.

b. Discrimination (anti-assimilation) activities will decrease (increase) if and only if the rent the migrant population can obtain from assimilation activities is greater than that of the rent of the local population, $r n_{I T}>n_{N}\left(r n_{I T}<n_{N}\right)$.

\subsection{Trade possibilities}

Now let us consider how the above changes, changes in the size of the migrant population $L_{F}$, and the rent received by the trader $r$, affect trade possibilities, $R=r \frac{a}{a+d} L_{F}=\frac{a}{a+d} b c$, where $b c=r L_{F} . \quad$ In general, we can write the following:

$$
\frac{\partial R}{\partial b}=c\left(\frac{d}{(d+a)^{2}} \frac{\partial a^{*}}{\partial b} b-\frac{a}{(d+a)^{2}} \frac{\partial d^{*}}{\partial b} b+\frac{a}{(d+a)}\right)
$$

Of course, this equation will be modified for each of the variables $L_{F}$, and $r$. First, it is clear that one has to determine if the direct effect, $\frac{a}{d+a}$, is stronger or weaker 
than the indirect effect, $\frac{d}{(d+a)^{2}} \frac{\partial a^{*}}{\partial b} b-\frac{a}{(d+a)^{2}} \frac{\partial d^{*}}{\partial b} b$. This is important to establish for the two effects may have different signs. The direct effect will be stronger than the indirect effect if $\eta+1>0$, where $\eta=\frac{d}{(d+a)^{2}} \frac{\partial a^{*}}{\partial b} \frac{b}{\frac{a}{(d+a)}}$ is the total elasticity of $\frac{a}{d+a}$ with respect to a change in $b$. It is not clear which effect is stronger. The second ambiguity that must be resolved is with respect to the elasticity $\quad \eta=\frac{d}{(d+a)^{2}} \frac{\partial a^{*}}{\partial b} \frac{b}{\frac{a}{(d+a)}}, \quad$ itself. It is clear that $\frac{d}{(d+a)^{2}}>0$ and $\frac{-a}{(d+a)^{2}}<0$ and the values of $\frac{\partial a^{*}}{\partial b}$ and $\frac{\partial d^{*}}{\partial b}$ are given in the analysis presented above. In this case we know that natives increase their discrimination activities and migrants their assimilation activities. The sign of $\frac{\partial R}{\partial L_{F}}$ will be equal to the sign of

$$
\frac{\partial R}{\partial L_{F}}=-r g(t)\left(\left(\frac{d}{(d+a)^{2}} \frac{-2 d}{(d+a)^{3}} r+\frac{-a}{(d+a)^{3}} \frac{-2 a}{(d+a)^{3}} L_{N}^{2} f^{\prime \prime}\right)+\frac{a}{d+a}\right)
$$

As we can see from (18), even though the effect of a change in the size of the migrant population has a positive effect on discrimination and assimilation activities, it is not clear which effect dominates overall trade possibilities. This will be a function of the strength in terms of gains and losses from such activities, as presented in proposition (1). This result is similar for changes in the other parameters $r$ and $t$ both of which determine the effect of trade possibilities. 


\section{Proposition 4}

Changes in the size of the migrant population, $L_{F}$, time, and the rent, $r$, have ambiguous effects on trade possibilities. The total effect is a result of the relative strength of the two groups in terms of benefits and ability to turn effort into gains, described in propositions (1)-(3).

The ambiguity regarding what will happen to the assimilation and anti-assimilation (discrimination) activities is resolved by looking at the results presented in the different propositions to see which of the groups has a stronger impact on the different activities.

\section{Trade Possibilities Over Time}

Here we look at the effect of networks over time. As assimilation progress, one network may grow stronger while the other becomes weaker. However, even though one becomes stronger, it may no longer be needed.

Each non-fully assimilated migrant is a representative of his home country and is a sales promoter of products from his home country. When migrants are not fully assimilated they continue to consume products from their home country, this consumption is observed by the natives of the host country and has a positive effect on the natives' consumption of products from the migrants' home country. When migrants become fully assimilated, their consumption of products from their home country decreases and their consumption patterns are identical to those of the native population. As assimilation increases, the advantages migrant traders have over native traders decline.

Earlier in the paper we discussed how assimilation increases trade opportunities. What is happening now is that international trader migrants want to increase ties with the local population in order to increase trade possibilities. As migrants assimilate, trade options may increase as a result of having more local networks and ties. However, the demand for products decreases as a result of the migrants themselves not consuming as many home products and this "promoter" of 
home products - the non-fully assimilated trader migrant - loses. We will observe over time the opposite consequences that these two effects have on trade possibilities. With time and assimilation, after a certain point the increase in benefits from assimilation are smaller then the losses from the decrease in the consumption of the imported products from the migrants country-of-origin.

As the assimilation process moving forward, trader migrants have more ties to the local population and can increase his trade possibilities with his home country. However, with time, even as his ties in the host country increase, his ties to his home country may well decrease. The trader migrant may now have fewer contacts in his home country and thus his trade possibilities decrease. Hence we assume that after some point in time, increasing assimilation does not have additional positive effects on trade possibilities from the host country. In terms of ties to the home country, with time there is a decrease in these ties.

To summarize, it is assumed that the rent from trade $R\left(\frac{a}{a+d} g(t) L_{F}\right)$ has two effects over time:

$$
\frac{d R_{t}\left(\frac{a}{a+d} L_{F}\right)}{d t}=\frac{\partial R_{t}\left(\frac{a}{a+d} L_{F}\right)}{\partial t}+\frac{\partial R_{t}\left(\frac{a}{a+d} L_{F}\right)}{\partial\left(\frac{a}{a+d} L_{F}\right)} \frac{\partial\left(\frac{a}{a+d} L_{F}\right)}{\partial t}
$$

The first component, $\frac{\partial R_{t}\left(\frac{a}{a+d} L_{F}\right)}{\partial t}$, represents the direct effect of time on the size of the rent from trade. For example, this can represent the decrease in trading possibilities as a result of a decrease in ties to the home country. The second component, $\frac{\partial R_{t}\left(\frac{a}{a+d} L_{F}\right)}{\partial\left(\frac{a}{a+d} L_{F}\right)} \frac{\partial\left(\frac{a}{a+d} L_{F}\right)}{\partial t}$, represents the indirect effect as a result of a change in ties to the host country. For example, it may capture an increase in ties to the local population and a decrease in the importation of home-country goods as a result of a high level of assimilation. 
In one scenario we could think of the case where until time $\bar{t}$ it is assumed that the effect of assimilation and the creation of host-country ties is stronger than the loss of ties in the home country and thus $\left.\frac{d R_{t}\left(\frac{a}{a+d} L_{F}\right)}{d t}\right|_{t \leq \bar{t}}>0$. However, over time and assimilation, the effect of the increase in ties to the host country has a very small effect on the trade possibilities, while there is a substantial decrease in the ties to the home country, therefore decreasing overall trade possibilities over time, $\left.\frac{d R_{t}\left(\frac{a}{a+d} L_{F}\right)}{d t}\right|_{t>\bar{t}}<0$. In this case we would see that until point $\bar{t}$ the trader migrant will gain from assimilation, with time his benefits from assimilation are initially increasing. However, after time $\bar{t}$, the trader will lose ties and his benefits from trade will decrease.

Consider the international trader migrant's utility as given by

$$
u_{t}(.)_{I T}=R_{t}\left(\frac{a}{a+d} L_{F}\right)-\left|a_{1 t}\right| \text {, }
$$

where, $a_{1}$ are assimilation activities, either for assimilation $a_{1}>0$ or against assimilation $a_{1}<0$. Denote by $a_{2}$ the activities of employed migrants. Therefore, $a$ $=a_{1}+a_{2}$. Under the assumption presented above we can conclude,

\section{Proposition 5}

There exists an inverse U-shaped relationship between the rent obtained from trade and time for the ethnic migrant. Moreover, with time the local population may well continue to invest in discrimination activities against the migrants, whereas the employed migrant population will invest in assimilation activities while the international trader migrants will increase assimilation activities until a certain point 
in time, $\bar{t}$, and beyond this time will decrease assimilation activities and may even invest in anti-assimilating activities $\left(a_{1}<0\right)$.

This proposition states that employed migrants benefit from assimilation and will invest in assimilation activities, $a_{2}>0$. At the beginning, the traders will benefit from assimilation and thus will increase their investment in assimilation activities (see figure 1 until point $\bar{t}$ ). Over time, after $\bar{t}$, the trader benefits less from insider ties and trade possibilities decrease (see figure 1). As a result, after period $\bar{t}$ assimilation activities by trader migrants decrease (see figure 2) and may even become negative. Negative assimilation activities can be thought of as anti-assimilation activities $\left(a_{1}<0\right)$, and include activities aimed at preserving home country traditions and emphasizing the differences between the local population and the migrants. At the same time the local population continues discriminating against migrants, while employed migrants continue to invest in assimilation activities.

It may well be the case that as employed migrants continue in their assimilation activities after a level of $a_{2}{ }^{*}$ and international traders invest effort in antiassimilation activities, $a_{l}$ becomes negative. Thus we see that the traders are fighting to prevent assimilation or at least full assimilation while the employed migrants from the same home country of the trader migrants' fight to increase assimilation. Both the local population and the traders will be fighting assimilation and the employed migrants fighting to increase assimilation. Over time, therefore, we may well see that the international trader migrants initially raise their assimilation efforts and fight discrimination, but after a certain point they go against their fellow country-men and decrease their assimilation activities, even engaging in anti-assimilation activities to hold on to their rent and not let the migrants fully integrate into the host country.

\section{Concluding remarks}

Rauch (2001) asks whether ethnic networks in international trade will grow or shrink in importance over time. His answer is two-fold. On the one hand, he appeals to the argument that in our increasingly integrated world international contracts now have some formal bite to them, diminishing the need for the sorts of "collateral" that ethnic networks can offer for traders. On the other hand, he points out that the information 
intensity of trade seems to complement transnational networks of the type that we have discussed. Our paper offers additional insights on this question, examining how those actors interact, affecting the assimilation path and international trade between the migrant's host and home countries.

Our picture of assimilation is simplified, focusing on the essential elements of migrant behavior in a host country, and the host country's receptivity to immigrants. Migrants want to assimilate, and as they assimilate their consumption patter come to mimic those of natives. Natives, fearful of lost earnings, try to keep immigrants isolated. Over time, subgroups of migrants who cater to the migrant community will take action against assimilation, arguing for maintaining elements of their cultural heritage and therefore the subgroups own rents. Though basic, the model allows us to gain insights that are helpful for understanding more complex assimilation scenarios (Gang and Zimmermann, 2000, Rapoport and Weiss, 2001).

Migrants and natives may possess asymmetrical ability and productivity. The degree of asymmetry will play a role in determining the intensity of assimilation activities by migrants and discrimination activities by natives. In turn, these determine the expansion and contraction of trade between migrants' host and home country. Over time, migrant traders and migrant employees exhibit different interests in assimilation and in maintaining their cultural identity, and the interplay of their conflict with the actions of the native-born over time provides further insights on the connection between ethnic networks and international trade. 


\section{References}

Bauer, Thomas and Klaus F. Zimmermann, 1997, Causes of International Migration: A Survey, in: C. Gorter, P. Nijkamp, and J. Poot (eds.), Immigrants, the City and the Labour Market. Aldershot, Brookfield (USA), Singapore, Sidney: Ashgate, 95-127.

Bauer, Thomas and Zimmermann, Klaus F., 2002, The Economics of Migration. Assimilation of Migrants. Vol. II. Edward Elgar Publishing Ltd. Cheltenham.

Chiswick, Barry, 1978, The Effect of Americanization on the Earnings of ForeignBorn Men, Journal of Political Economy, 86 (5), 897-922.

Duleep, Harriet, and Mark Regets, 2002, The Elusive Concept of Immigrant Quality: Evidence from 1970-1990, IZA discussion paper 631 (www.iza.org).

Epstein, Gil S. 2003, Labor Market Interactions Between Legal and Illegal Immigrants, Review of Development Economics, 7(1), 2003, 30-43.

Epstein, Gil S. and Shmuel Nitzan, 2004, Reduced Prizes and Increased Effort in Contests, Social Choice and Welfare, forthcoming.

Gang, Ira N. and Rivera-Batiz, Francisco, 1994, Labor Market Effects of Immigration in the United States and Europe: Substitution vs. Complementarity, Journal of Population Economics, 7 (1994) 157-175.

Gang, Ira N. and Klaus F. Zimmermann, 2000, Is Child Like Parent? Educational Attainment and Ethnic Origin, Journal of Human Resources, 35 (2000) 550569.

Le, Anh T, 1999, Empirical Studies of Self-Employment Journal of Economic Surveys, (4), 381-416.

Lindbeck, Assar and Dennis J. Snower, 1988, Cooperation, Harassment, and Involuntary Unemployment, An Insider-Outsider Approach, American Economic Review, 78(1) 167-188.

Lofstrom, Magnus, 2002, Labor Market Assimilation and the Self-Employment Decision of Immigrant Entrepreneurs, Journal of Population Economics, 15 (1), 83-114. 
Lockard, A. and Tullock, G. (2001), Efficient Rent Seeking: Chronicle of an Intellectual Quaqmire, Kluwer (Boston).

Morduch, Jonathan, 1999, The Microfinance Promise, Journal of Economic Literature 37(4), 1569-1614.

Rapoport, H. and A. Weiss, 2001, The Optimal Size for a Minority, IZA (Institute for the Study of Labor) DP 284, Bonn.

Rauch, James E., 2001, Business and Social Networks in International Trade, Journal of Economic Literature, 39 (4), 1177-1203.

Tullock, Gordon. (1980). “Efficient Rent-seeking” In James M. Buchanan, Robert.D. Tollison, and Gordon Tullock, editors, Toward a Theory of the Rent-seeking Society (College Station, Texas A\&T Press). 
Figure 1: Trade possibilities

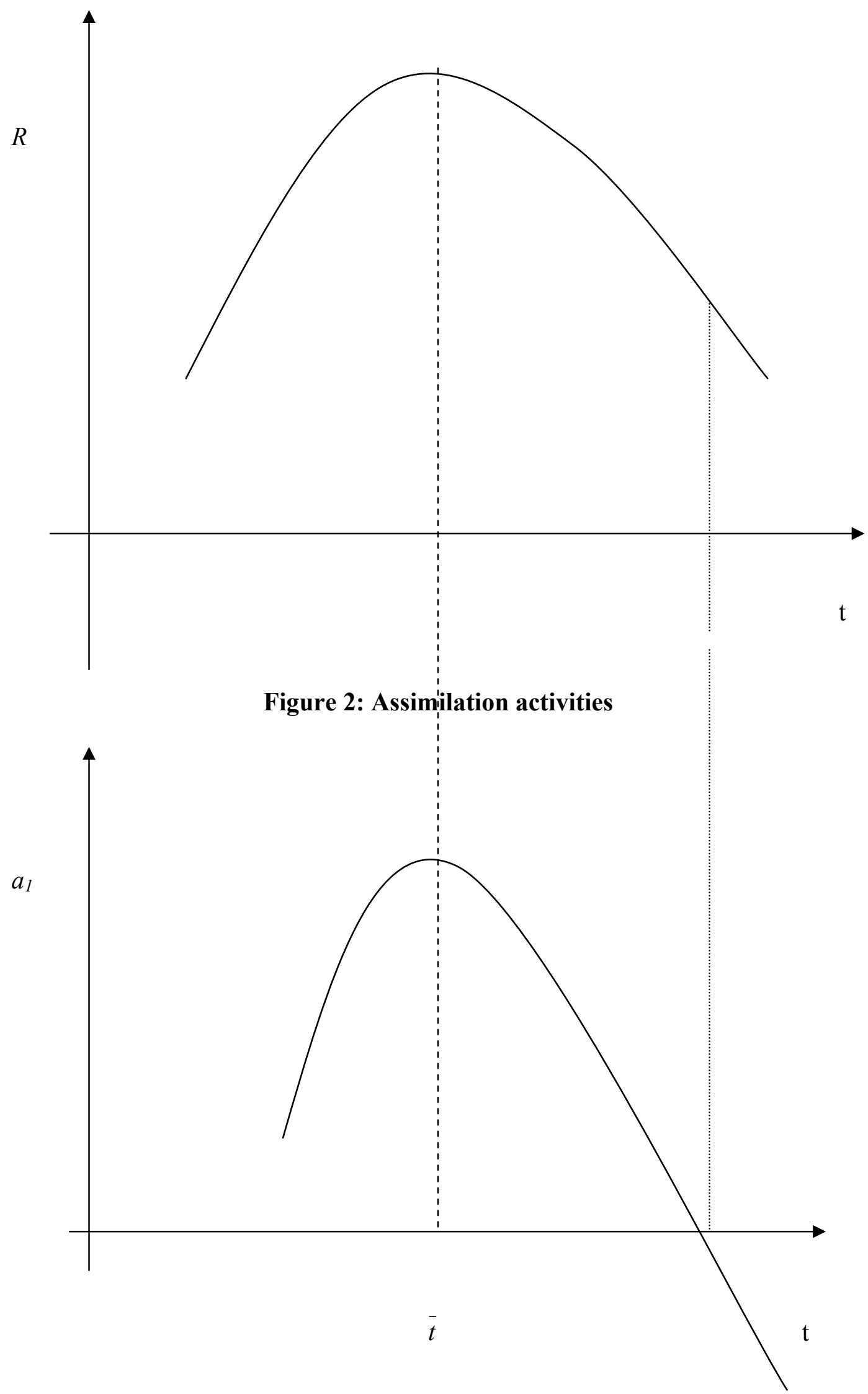

